\title{
Application of remote sensing to informal garbage dumps recognizing in beijing city
}

\author{
Bin Cheng ${ }^{1, *}$, and Libo Sun $^{2}$ \\ ${ }^{1}$ College of Geographic Sciences Changchun Normal University, Changchun 130021, China \\ ${ }^{2}$ Northeast Institute of Geography and Agroecology Chinese Academy of Sciences, Changchun \\ 130102, China
}

\begin{abstract}
The improvement of urbanization level and the imperfection of waste treatment infrastructure have caused the problem that informal garbage dump become prominent problem in China. With the development of high resolution remote sensing images, the fast monitoring and management of informal garbage dumps become possible. The informal garbage dumps in Beijing are monitored by SPOT-6 image, and the rapid and accurate grasp of the number, position and size of the informal garbage dumps are identified by the establishment of the interpretation key using multivariate data. And then it is classified by the established interpretation key. Irregular garbage sites are uneven in shape and complex in composition, which leads to their atypical features in images. Visual interpretation and classification are more suitable for other methods.
\end{abstract}

\section{Introduction}

In recent years, with the improvement of urban living and residents consumption, municipal solid waste production increase continually, producing a large number of municipal solid waste simple landfill and air storage due to inadequate waste management and treatment facilities. Informal dumps direct poses a direct threat to the soil, groundwater and air, as well as a large impact on the lives of the residents to the surrounding environment[1]. Monitoring and management of informal dump sites is a serious problem, and traditional methods of field survey is laborious and time-consuming. With the increasing resolution of remote sensing images and the increasing variety of data, it is possible to use remote sensing images to monitor and manage informal garbage sites.

Remote sensing has the characteristics of macroscopic, timeliness, current situation and economy, etc. It is an effective and rapid means for monitoring informal garbage sites. Through remote sensing monitoring, statistics on informal garbage dumps are obtained and trends in informal garbage dumps are available to provide a basis for governance.

Remote sensing has been applied to site selection and hazard assessment of garbage landfill sites, while it is rarely used to identify and monitor them. The information available is only monitored by aerial photographs. Wu wenwei [2]investigated solid waste stacking and filling in the five ring road in Beijing using aerial remote sensing technology.Zhao

* Corresponding author: cb_gis@sina.com 
Jing[3] obtained the garbage interpretation target mark. Aerial photography is characterized by high spatial resolution and easy identification of ground objects. However, due to its high cost and long acquisition cycle, it is difficult to meet the requirements of real-time monitoring of garbage sites. Liu Yalan conducted interpretation analysis and change detection research on informal garbage sites using Beijing-1images in Beijing[4].

\section{Informal garbage dumps and their hazards}

Informal garbage dumps are landfills that do not conform to the relevant national policies, regulations and standards for construction and operation, including household waste, construction waste and mixed waste, commonly known as garbage dumps and garbage mountains. The main components of household garbage are household waste, including recyclable paper, metal, plastic and glass, kitchen waste such as food waste such as leftovers, bones, vegetable roots and leaves, as well as harmful waste such as waste batteries, waste fluorescent lamp tubes, waste water silver thermometer, expired medicine and medical waste. The main components of construction waste are bricks, tiles, ceramics, muck, abandoned soil, materials, mud and other wastes generated during the construction, laying, dismantling and repairing of various buildings, structures and pipe networks by construction units or individuals. The composition of mixed garbage is relatively complex, including not only the domestic waste, but also the bricks, tiles, ceramics and muck of construction garbage. Compared with household garbage and construction garbage, mixed garbage has certain difficulty in management.

There are 16 municipal districts in Beijing, and most of the informal dumps in Beijing are located on the outskirts of the city.Within the fifth ring road, the distribution of informal dumps is very small., and the number of informal rubbish dumps is increasing, between the fifth ring and the sixth ring road. Outside the sixth ring road, the number of them is highest.

With the expansion of cities and the increase of population, there is more and more garbage in cities, and the harm caused is obvious. First, garbage dumps occupies a lot of land. Secondly, there are a variety of pathogenic microorganisms, acid and alkaline pollutants and heavy metal pollutants in garbage. Garbage near water systems can directly pollute the source of water and permeate soil and groundwater. Garbage can produce harmful gases and pollute the atmosphere. At the same time, garbage dumps affect urban environmental sanitation, and they are also the activity place for a large number of mosquitoes, flies and rats[3].

\section{Remote sensing image}

The multi-temporal panchromatic and multispectral images of SPOT-6 were used in this paper. Panchromatic and multispectral fusion images can cover all plain areas of Beijing. The processing of remote sensing images include radiometric correction, image clipping, mosaic, fusion, image toning, image reprojection, etc.

\section{Informal garbage dumps interpretation key}

Remote sensing image interpretation is the process of obtaining the target feature information from the image, which is divided into visual interpretation and computer interpretation. Visual interpretation refers to the process in which professionals obtain the information of specific objects from remote sensing images by direct observation or by means of instruments. The characteristics of target features in remote sensing images are 
typical reflections of electromagnetic radiation differences of surface features in images, including color, shape and position according to their different forms of manifestation[5].

In order to identify the informal garbage dumps, it is necessary to establish the relevant interpretation marks. But it is time-consuming and difficult to achieve the interpretation them through field investigations. In the study, we gradually took the characteristics of the informal garbage dumps in the SPOT-6 satellite image and formed the interpretation mark, according to the existing distribution location of the landfill and the field investigations and the reference of some aerial photograph.

\subsection{Color}

The composition of the informal junkases is complex, and the corresponding spectral characteristics are complex, so its the reflectivity of remote sensing images is different. Household solid waste in the image is white and virtual (non-image quality problem), and the image of the surrounding image is different, and it is easy to identify the irregular household solid waste in the high-resolution image. The color of building waste and industrial waste is gray or highly bright, and the color of the large landfill is different from the ground objects. The color is not single, and the various colors are dotted with spots. Buildings or roads show a single color in different shapes by certain rules.

\subsection{Shape}

Natural or artificial garbage dump is an irregular shape, and the boundary is not obvious. The normal landfill field has a more regular boundary.

\subsection{Size}

The size of the dumps is related to the distribution of the residential area, and if the residential area is concentrated, the area of the landfill will be more large. Conversely, it will be smaller.

\subsection{Texture}

The rubbish has obvious texture characteristics, and the household solid waste appears to be fluffy, gray and rough.

\subsection{Position}

There is no large informal garbage dump within the residential concentration area. The informal landfill is generally located around the residential concentration area, which is relatively close to the residents, and the traffic is relatively convenient, and it is usually piled up in the pond or in the desert, and the landfill is usually bumpy and irregular. There is a path connection and the path is interrupted.

\section{Interpretation analysis of informal garbage dumps}

The identification of informal garbage dump requires a variety of information comprehensive interpretation analysis, which must be combined with the establishment of an informal dump interpretation key, the location of the existing informal landfill and the 
map of the land use. On the basis of the interpretation remote sensing image of indoor, the field survey is also carried out to ensure the accuracy and reliability of the results of the interpretation. There are three reasons for error judgment or omission in the informal dump interpretation.(1)Its external form is similar to the dump, and most of the building dumps are the rubble and the brick and tile and mound.(2)The surface of the informal dump is flat and the surface is not covered with soil, no obvious concave feeling, easy to cause error judgment and omission judgment.(3)Due to seasonal changes and weather reasons, the surface of the informal landfill is caused by grass or snow cover, which is prone to error and omission. The solution is to identify the relationship between the surrounding objects by comparing the analysis of the multi-temporal image.

\section{Conclusion}

Using the SPOT-6 image, the number of informal garbage dumps in Beijing is constantly decreasing by comparison of the Beijing remote sensing monitoring data in 2015 and 2017 from 300 in early 2015 to 50 in the end of 2017. Especially in the fall of 2017, the party's 19th national meeting was about to be held, in order to create a clean Beijing city, and the authorities were actively working on the irregular junkies, leading to a rapid reduction in the number of informal garbage dumps in Beijing to about 20 or so, but a rebound in the latter stage.

Through the field verification of the results of the information extraction, the accuracy of remote sensing interpretation is more than $90 \%$. As the city's population suddenly increased, the amount of waste was increasing. Although the efforts of the relevant departments have been strengthened, the lack of existing waste disposal facilities, the increase in the number of informal garbage dumps, is an inevitable matter.

Panchromatic and multi-spectral fusion SPOT-6 images were used in this study. Both the temporal and spatial resolution of SPOT-6 images can meet the needs of informal garbage dumps identification, which not only ensures the timeliness of the investigation, but also saves the cost to a large extent. Moreover, the investigation speed is much higher than that of traditional ground investigation methods. By using the identification results, supplemented by land use maps, informal garbage sites in the city are generated as thematic information maps, which provide powerful and detailed data support for the government departments to accurately grasp their locations, quantities and scales.

It is a meaningful attempt and exploration to monitor informal garbage sites by means of remote sensing, and satisfactory results have been achieved. The research shows that satellite remote sensing is completely feasible to obtain information related to urban environmental health.

This work was supported by National Natural Science Foundation of China (NSFC) (41801010).

\section{References}

1. Guo Y.. Designerly Research into the Landscape Conversion of Irregular Landfills Surrounding Beijing City. Tsinghua University,(2012).

2. Wu WW., Liu J.. The Application of Remote Sensing Technology on the Distribution Investigation of the Solid Waste in Beijing. ESE,8 (2):76-78,(2000).

3. Zhao J., Zang K., Gong H.L.. The Application of Remote Sensing Technology on the Distribution and Disposal of Garbage in Beijing. JCNU,26(3):109-113,(2005).

4. Liu Y.L., Ren Y.H., Wei C.J.,et,al. Study on monitoring of informal open air solid waste dumps based on Beijing-1images.JRS,13(2):320-326,(2009). 
5. Mei A.X.,Peng W.L.,Qing Q.M.,et,al. Introductory of Remote Sensing(Higher Education Press, 2001). 